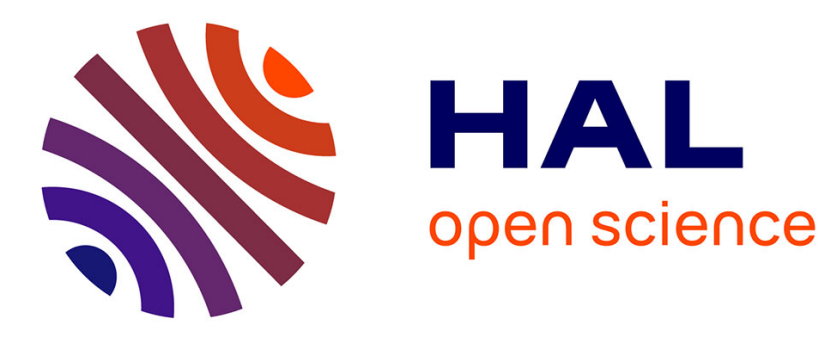

\title{
Broadband integrated racetrack ring resonators for long-wave infrared photonics
}

\author{
Joan Manel Ramírez, Qiankun Liu, Vladyslav Vakarin, Xavier Le Roux, \\ Jacopo Frigerio, Andrea Ballabio, Carlos Alonso-Ramos, Enrico Talamas \\ Simola, Laurent Vivien, Giovanni Isella, et al.
}

\section{To cite this version:}

Joan Manel Ramírez, Qiankun Liu, Vladyslav Vakarin, Xavier Le Roux, Jacopo Frigerio, et al.. Broadband integrated racetrack ring resonators for long-wave infrared photonics. Optics Letters, 2019, 44 (2), pp.407. 10.1364/OL.44.000407 . hal-01983394

\section{HAL Id: hal-01983394 https://hal.science/hal-01983394}

Submitted on 16 Jan 2019

HAL is a multi-disciplinary open access archive for the deposit and dissemination of scientific research documents, whether they are published or not. The documents may come from teaching and research institutions in France or abroad, or from public or private research centers.
L'archive ouverte pluridisciplinaire HAL, est destinée au dépôt et à la diffusion de documents scientifiques de niveau recherche, publiés ou non, émanant des établissements d'enseignement et de recherche français ou étrangers, des laboratoires publics ou privés. 


\title{
Broadband integrated racetrack ring resonators for long-wave infrared photonics
}

\author{
JoAn Manel Ramirez, ${ }^{1, *}$ QIANkun LiU, ${ }^{1,+}$ Vladyslav Vakarin, ${ }^{1,+}$ XaVier Le \\ ROUX, ${ }^{1}$ JACOPO FrIgERIO, ${ }^{2}$ ANDREA BALLABIO, ${ }^{2}$ CARlOS AlONSO-RAMOS, ${ }^{1}$ \\ Enrico Talamas Simola, ${ }^{2}$ LAUREnT VIVIEN, ${ }^{1}$ GIOVANNI ISELLA, ${ }^{2}$ AND DelPhine \\ MARRIS-MORINI ${ }^{1}$ \\ ${ }^{1}$ Centre de Nanosciences et de Nanotechnologies (C2N), Université Paris Sud, CNRS, Université Paris Saclay, 91405 Orsay, France \\ ${ }^{2}$ L-NESS, Dipartimento di Fisica, Politecnico di Milano, Polo di Como, Via Anzani 42, 22100 Como, Italy \\ *Corresponding author: joan-manel.ramirez@u-psud.fr \\ + Both authors contributed equally to this work
}

Received XX Month XXXX; revised XX Month, XXXX; accepted XX Month XXXX; posted XX Month XXXX (Doc. ID XXXXX); published XX Month XXXX

Long-wave infrared photonics is an exciting research field meant to revolutionize our daily life by means of key advances in several domains including communications, imaging systems, medical care, environmental monitoring or multi-spectral chemical sensing, among others. For this purpose, integrated photonics is particularly promising owing to its compactness, mass fabrication and energy-efficient characteristics. We present in this letter, for the first time to the best of our knowledge, broadband integrated racetrack ring resonators operating within the crucial molecular fingerprint region. Devices show an operation bandwidth of $\Delta \lambda \approx 900 \mathrm{~nm}$ with a central wavelength of $\lambda \approx 8 \mu \mathrm{m}$, a quality factor of $Q \approx 3200$ and an extinction ratio of $E R$ $\approx 10 \mathrm{~dB}$ around the critical coupling condition. These resonant structures establish the basis of a new generation of integrated building blocks for long-wave infrared photonics that open the route towards miniaturized multi-target molecule detection systems.

OCIS codes: (130.3120) Integrated optics devices, (230.5750) Resonators, (130.3060) infrared, (280.4788) Optical sensing and sensors.

http://dx.doi.org/10.1364/OL.99.099999

Mid infrared (mid-IR) photonics is becoming an interesting research field due to the wide plethora of applications foreseen in different arenas of our society, including high-resolution biosensing, early medical diagnosis, security, free-space optical communications, defense, 3D imaging, and many more [1-3]. Among them, the identification of molecules via vibrational spectroscopy in the longwave infrared (LWIR) range using photonic integrated circuits (PICs) has been a subject of intense research due to the expected superior performance compared to other existing approaches [4]. In this regard, silicon (Si) photonics is expected to have a high impact in mid-IR photonics. Indeed, Si photonics provides a reliable and high volume platform that leverages from a mature technology that has been largely employed by now to develop solutions in the near IR wavelength range, notably for telecom/datacom applications [5]. However, the extension of the operation wavelength range of conventional siliconon-insulator (SOI) waveguides towards the mid-IR is not straightforward due to the optical absorption of the buried $\mathrm{SiO}_{2}$ layer for wavelengths beyond $\lambda=3.6 \mu \mathrm{m}$. Different approaches have been proposed to extend Si photonics towards the mid-IR, including the implementation of waveguide engineering strategies to minimize the mode overlap with the bottom cladding [6], the use of pedestal waveguides [7] or the development of suspended membranes [8, 9]. While these approaches can be successful below $8 \mu \mathrm{m}$ wavelength, according to the Si mid-IR transparency window, alternative solutions are required to exploit larger mid-IR wavelengths. For this purpose, germanium (Ge) stands as a promising material owing to its extended transparency up to $\lambda=15 \mu \mathrm{m}$, its CMOS technology maturity, its high third-order nonlinearity and its large refractive index that makes it suitable to implement compact integrated devices with a small footprint. Therefore, germanium-on-silicon has been often chosen as a platform to implement LWIR PICs, as can operate over a wide wavelength range within the molecular fingerprint region $(5 \mu \mathrm{m}<\lambda<$ $12 \mu \mathrm{m}$ ) with low/moderate propagation loss [10-13]. Similarly, graded silicon-germanium ( $\mathrm{SiGe}$ ) has also been employed as an enabling integrated platform, as it permits a gradual accommodation of the lattice mismatch between $\mathrm{Si}$ and Ge, hence obtaining a Ge-rich SiGe epilayer with good crystalline quality and low defect density [14]. Thus, graded-index SiGe alloys benefit from the advantages of Ge while providing high versatility in terms of mode confinement, as their optical properties can be effectively controlled by careful engineering of the vertical refractive index profile [15]. Recently, we have demonstrated several broadband LWIR photonic components and building blocks using the graded-index SiGe platform, including lowloss and polarization-insensitive waveguides [16, 17], Mach-Zehnder interferometers [18], dual-polarization Fourier Transform 
spectrometers [19] or Bragg grating Fabry-Perot cavities [20]. Furthermore, a preliminary LWIR sensing proof-of-concept has also been realized between $5.2 \mu \mathrm{m}$ and $6.6 \mu \mathrm{m}$ wavelengths [21]. In this context, the implementation of micro-ring resonators appears interesting, as it has many utilities in integrated photonics, such as its implementation as i) a notch filter to finely select and reject narrow frequency bands; ii) a compact sensor that effectively increases the interaction length between the propagating mode and the analyte; iii) an elementary unit for optical delay lines; iv) an efficient modulator or v) a nonlinear device, which provides a strong-light matter interaction with the nonlinear material to generate frequency combs around the pumping wavelength [22]. Current development of LWIR ring resonators is still in its infancy, with demonstrations that cover a wavelength span of $\lambda=2.75-5.6 \mu \mathrm{m}$ [23-26], a range that remains insufficient for the envisioned applications of LWIR integrated platforms [27]. It is worth to note that extending the operation range of ring resonators well into the LWIR wavelength range is not trivial as the use of Ge-based integrated platforms with a relatively low index contrast could compromise the compactness of the ring resonator and ultimately the maximum free-spectral range attainable; In the following, we will show that by a careful design of the resonators LWIR integrated racetrack ring resonators can be implemented.

In this letter, we demonstrate for the first time an integrated LWIR racetrack ring resonator implemented on a Ge-rich SiGe material platform that works at long-wave infrared wavelengths around $\lambda \approx 8$ $\mu \mathrm{m}$, shows a maximum loaded quality factor (Q) of 3200, offers a high LWIR bandwidth $(\Delta \lambda)$ of $900 \mathrm{~nm}$ and a maximum extinction ratio (ER) of $10 \mathrm{~dB}$. These results demonstrate that integrated long-wave resonant structures are feasible using Ge-rich graded-index SiGe layers, opening up the way towards advanced LWIR PICs.

Racetrack ring resonators were developed in a $6 \mu \mathrm{m}$ thick gradedindex SiGe layer grown by Low Energy Plasma Enhanced Chemical Vapor Deposition (LEPECVD) [28]. A linear increase of the Ge concentration along the growth direction from $\mathrm{Si}$ up to pure Ge is used to confine light on the upper part of the waveguide. Waveguides are then designed using a rib-like geometry with an etching depth of $3 \mu \mathrm{m}$ and a width of $4 \mu \mathrm{m}$. Further details of this platform can be found elsewhere [29]. Racetrack resonators were designed to operate at $\lambda \approx 8$ $\mu \mathrm{m}$ taking into account several requirements. Firstly, the directional couplers have to provide a power coupling factor $\left(\mathrm{k}^{2}\right)$ able to compensate for one round-trip loss in the resonator. The gap distance (g) and coupling length (L) have then been chosen as $g=1 \mu \mathrm{m}$ and $\mathrm{L}=200 \mu \mathrm{m}$ to ease fabrication process keeping reasonable aspect ratio for the gap definition, while maintaining a compact device footprint and a free-spectral-range (FSR) above the minimum wavelength resolution of the experimental set-up, which is around $1 \mathrm{~cm}^{-1}$. Figure 1 shows an example of simulation of the $\mathrm{E}_{\mathrm{y}}$ component of the even (Fig. 1. a) and odd (Fig. 1. b.) quasi-TM supermodes in the directional coupler. The power coupling factor was deduced for a coupling length of $\mathrm{L}=200 \mu \mathrm{m}$, as reported in Fig 1.c. Interestingly, the achieved value, $\mathrm{k}^{2} \approx 0.2$, is compatible with the propagation loss in the resonator cavity of a few $\mathrm{dB} / \mathrm{cm}$. A remarkable flat profile of $\mathrm{k}^{2}$ from 7.5 to $8.5 \mu \mathrm{m}$ is observed, with a moderate linear increase from $\mathrm{k}^{2}=0.1(\lambda=7.5 \mu \mathrm{m})$ to $\mathrm{k}^{2}=0.35(\lambda=8.5 \mu \mathrm{m})$, denoting the ability of these directional couplers to operate over a broadband at LWIR wavelengths. This phenomenon is attributed to the particular combination of a low material dispersion at these wavelengths and the propagating mode re-adaptation induced by the vertical graded-index profile [15].

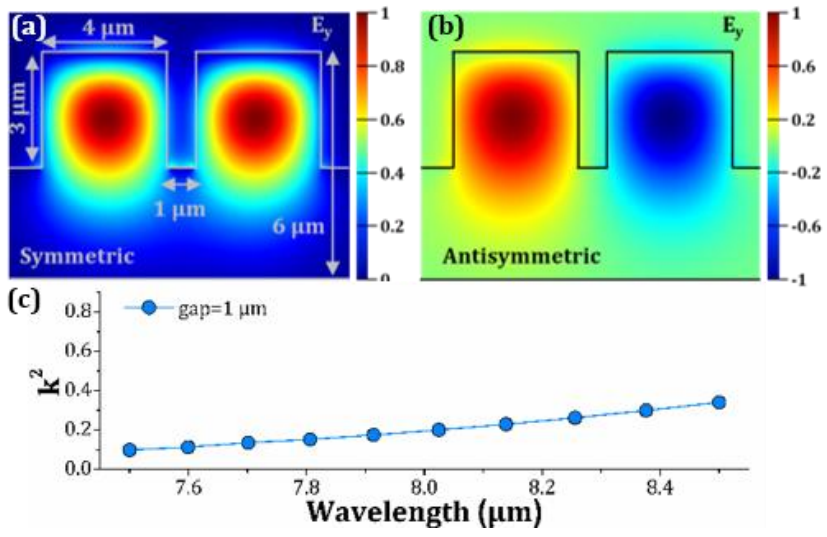

Fig. 1. Even (a) and odd (b) quasi-TM guided supermodes of the directional coupler containing graded-index SiGe waveguides. Waveguide width is $4 \mu \mathrm{m}$, the etching depth is $3 \mu \mathrm{m}$ and the gap between the waveguides is $1 \mu \mathrm{m}$. (c) Simulated power coupling factor, $\mathrm{k}^{2}$, for a coupling length of $\mathrm{L}=200 \mu \mathrm{m}$ from $\lambda=7.5 \mu \mathrm{m}$ to $8.5 \mu \mathrm{m}$.

Similarly, the bending radius of racetrack ring resonators was chosen considering the trade-off between the reduction of the round-trip loss (by increasing the bending radius) and the minimum FSR value imposed by our experimental setup. Based on these considerations, and taking into account previously reported propagation losses of 2-3 $\mathrm{dB} / \mathrm{cm}$ [29], 5 different bending radius between $\mathrm{R}=50 \mu \mathrm{m}$ and $\mathrm{R}=$ $250 \mu \mathrm{m}$ were selected.

Racetrack ring resonators were fabricated using e-beam lithography followed by a selective ICP etching. Fig. 2. a. presents a cross-section scanning electron microscopy (SEM) image of the coupling region of a test resonant structure. A top SEM view of a racetrack ring resonator with $\mathrm{R}=100 \mu \mathrm{m}$ is shown in Fig. 2. b. After fabrication, waveguide facets were diced to facilitate butt-coupling of the free-space laser beam. Devices were characterized using an external cavity quantum cascade laser operating in quasi-TM polarization and in pulsed regime (duty cycle of $5 \%$ and repetition rate of $100 \mathrm{kHz}$ ), with a linewidth specified to be below $1 \mathrm{~cm}^{-1}$. A wavelength range from $\lambda=7.5 \mu \mathrm{m}$ $\left(1333.3 \mathrm{~cm}^{-1}\right)$ to $8.6 \mu \mathrm{m}\left(1162.8 \mathrm{~cm}^{-1}\right)$ was investigated.

The input/output signals were coupled in and out of the chip by means of $\mathrm{ZnSe}$ aspheric lenses, obtaining a typical coupling loss of $4 \mathrm{~dB} /$ facet. The collected signal was sent through either a high-resolution camera to visualize the spatial profile of the propagating mode or to an $\mathrm{HgCdTe}$ (MCT) detector to scan the transmission spectrum. 

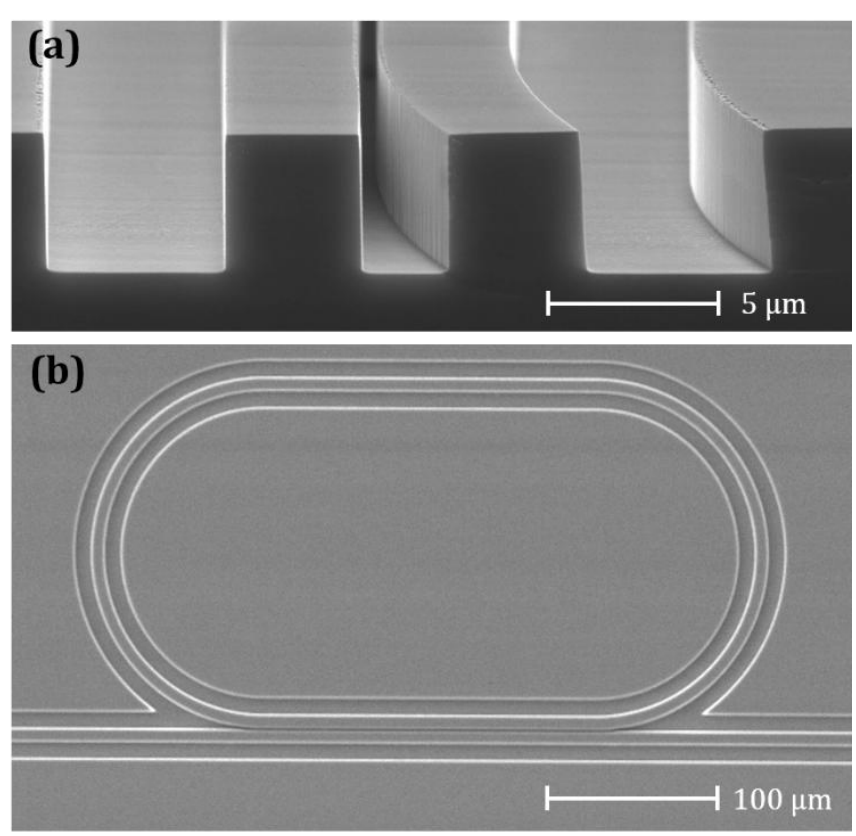

Fig. 2. (a) Cross-section SEM view of a test resonator device in the coupling area. (b) Top SEM view of a racetrack ring resonator.

Figure 3 summarizes the normalized quasi-TM transmission of the racetrack ring resonators with increasing radius of curvature in a bottom-up arrangement. The characteristic interferometric pattern of ring resonators is observed, presenting periodic transmission dips that are sometimes partially clipped due to the limited resolution of our setup. Noticeably, the lowest radius of curvature, i. e. $R=50 \mu \mathrm{m}$, shows a poor performance with resonance patterns of $4 \mathrm{~dB}$ in average and a multimode-like spectrum that deforms the transmission curve. This fact can be attributed to a partial hybridization of the modes, obtaining a non-negligible conversion of the fundamental quasi-TM mode into quasi-TE polarization (in agreement with FEM simulations). Furthermore, a remarkably higher bending loss is to be expected compared to other structures, hence shifting the critical coupling condition to gap values lower than $1 \mu \mathrm{m}$. Indeed, we are still able to observe asymmetric resonances for the resonator having an $\mathrm{R}=100$ $\mu \mathrm{m}$, which are equally attributed to a mode hybridization effect, although much weaker. Moreover, it is worth noting the superimposed modulation of the interferometric pattern, causing oscillations of the resonance depth, which are typically attributed to the oscillatory behavior of the transmitted signal in the directional couplers [30].

In order to verify the fundamental mode operation of the devices for $\mathrm{R}$ $>50 \mu \mathrm{m}$, the FSR of the resonances was measured as a function of the wavelength and compared with the theoretical model assuming the following equation:

$F S R=\frac{\lambda^{2}}{n_{g} L}$

Where $n_{g}$ is the group refractive index of the propagating mode, $\lambda$ is the operating wavelength and $L$ is the round-trip length. Figure 4 presents the dispersion of the FSR for each bending radius, with the theoretical model of equation 1 superimposed assuming an $n_{g}=3.8$. As seen, bigger FSR values were measured for lower bending radius, as expected. Moreover, good agreement between the experimental results and the modeling was found, providing evidence that the observed resonances correspond to a single propagating mode inside racetrack ring resonators.
Concerning the transmittance response, resonators with $\mathrm{R}>50 \mu \mathrm{m}$ display deep resonances with an ER up to $10 \mathrm{~dB}$. Figure 3(b) shows a zoomed-in view of a resonance corresponding to the biggest racetrack resonator $(\mathrm{R}=250 \mu \mathrm{m})$. A lorentzian fit is used to extract the full width at half maximum (FWHM), which will ultimately be used to extract the loaded quality factor:

$$
Q=\frac{\lambda_{\text {central }}}{F W H M}
$$

A maximum loaded quality factor of $Q \approx 3200$ is measured at $\lambda \approx 8.044$ $\mu \mathrm{m}$, which correspond to a FWHM of $0.38 \mathrm{~cm}^{-1}$. When compared to the laser linewidth used in the experiment $\left(<1 \mathrm{~cm}^{-1}\right)$ we can deduce that the measured resonance spectral shape and Q-factor are most probably limited by the experimental set-up. Interestingly, the critical coupling wavelength (around of 8.1-8.2 $\mu \mathrm{m}$ ) is compatible with waveguide propagation loss of $3 \mathrm{~dB} / \mathrm{cm}$ and negligible bend loss for $\mathrm{R}>150 \mu \mathrm{m}$ [29].
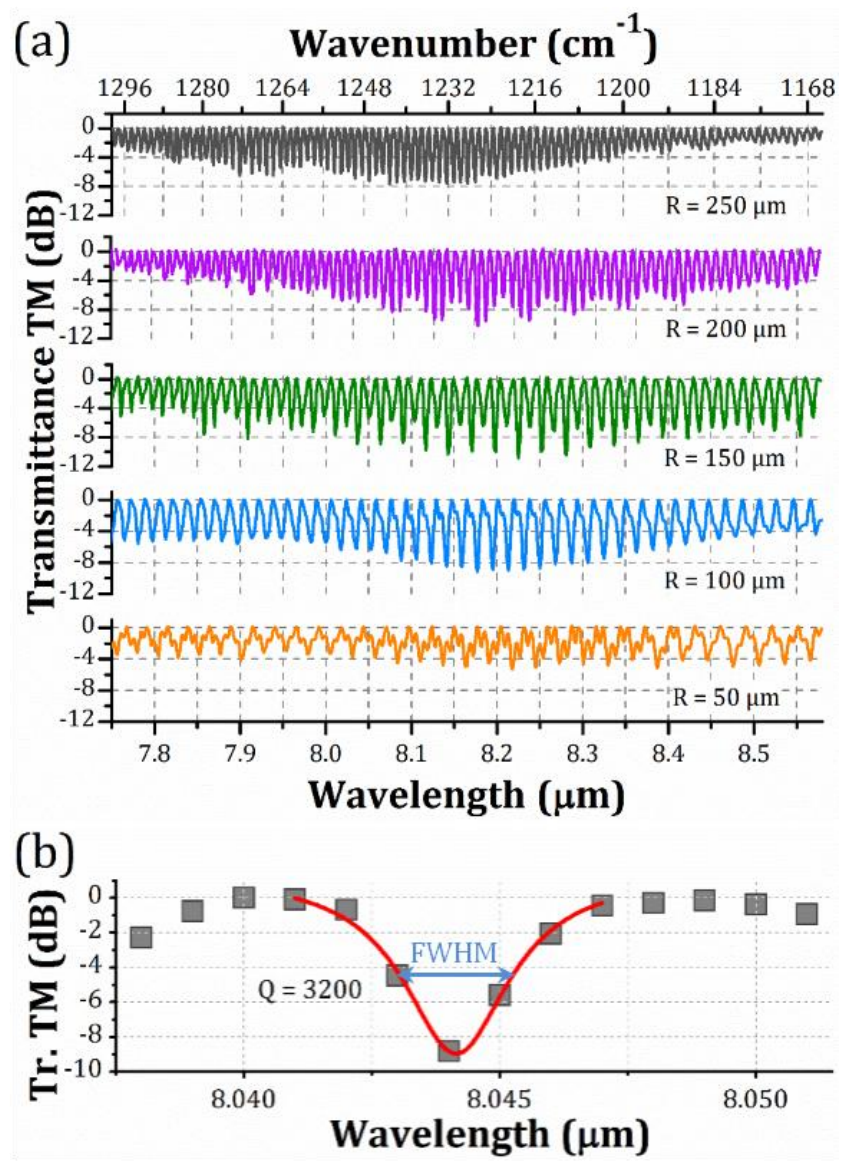

Fig. 3. (a) Experimental transmission spectra of racetrack ring resonators operating in quasi-TM polarization and arranged according to increasing bending radius. From bottom-up, $\mathrm{R}=50 \mu \mathrm{m}$ (orange curve), $\mathrm{R}=100 \mu \mathrm{m}$ (light blue), $\mathrm{R}=150 \mu \mathrm{m}$ (green), $\mathrm{R}=200 \mu \mathrm{m}$ (violet) and $\mathrm{R}=250 \mu \mathrm{m}$ (grey curve). (b) Zoomed-in view of a single resonance (grey squares), corresponding to a resonator with $\mathrm{R}=250$ $\mu \mathrm{m}$, showing a lorentzian fit (red curve) and a calculated quality factor of $Q=3200$.

In conclusion, we have shown the first demonstration of broadband integrated racetrack ring resonators for long-wave infrared photonics that operate around $8 \mu \mathrm{m}$ wavelength. The resonant structures have been implemented using a $6 \mu \mathrm{m}$-thick Ge-rich graded-index SiGe 
platform that contains a linear increase of the Ge concentration in the vertical direction. Devices show a bandwidth of $\Delta \lambda \approx 900 \mathrm{~nm}$, a maximum quality factor of $Q=3200$ and an extinction ratio of $10 \mathrm{~dB}$ around the critical coupling condition. This work paves the way towards the implementation of multi-target molecular spectroscopic sensors in integrated photonic platforms.

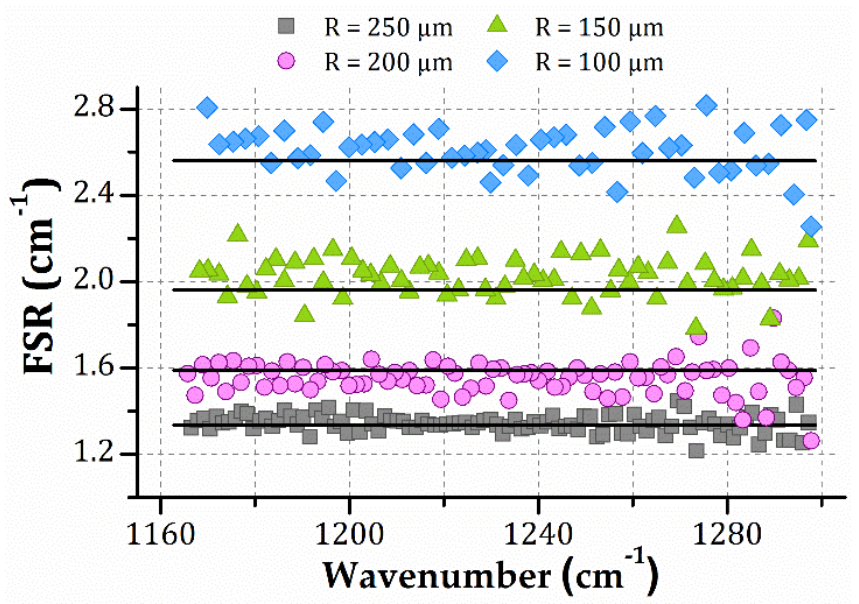

Fig. 4. Measured FSR values as a function of wavelength and the bending radius, being the gray squares $R=250 \mu \mathrm{m}$, the light-pink dots $\mathrm{R}=200 \mu \mathrm{m}$, the green triangles $\mathrm{R}=150 \mu \mathrm{m}$ and the light-blue lozenges $\mathrm{R}=100 \mu \mathrm{m}$. Straight black lines correspond to the expected spectral response according to equation 1 for an $n_{g}=3.8$.

Funding. European Research Council (ERC) under the European Union's Horizon 2020 research and innovation program (N639107-INsPIRE). A. Ballabio acknowledges financial support by the TEINVEIN project funded by POR FESR 2014-2020 (ID: 242092). J. Frigerio acknowledges financial support by the European Union Horizon 2020 FET project microSPIRE (ID: 766955).

Acknowledgment. The fabrication of the device was performed at the Plateforme de Micro-Nano-Technologie/C2N, which is partially funded by the "Conseil Général de l'Essonne". This work was partly supported by the French RENATECH network.

\section{References}

1. R. Soref, Nature Photonics, 4, 495 (2010).

2. J. Haas, B. Mizaikoff, Annual Review of Analytical Chemistry, 9, 45 (2016).

3. X. Wang, S. S. Kim, R. Roßbach, M. Jetter, P. Michler, and B. Mizaikoff, Analyst, 137, 2322 (2012).

4. Y. Chen, H. Lin, J. Hu and M. Li, ACS nano, 8, 7, 6955 (2014).

5. R. Soref, IEEE J. Sel. Top. Quantum Electron. 12, 6 (2006).

6. S-A. Miller, M. Yu, X. Ji, G. Griffith, J. Cardenas, A-L. Gaeta, and M. Lipson, Optica, 4, 7, 707 (2017).

7. P-T. Lin, V. Singh, J. Hu, K. Richardson, J-D. Musgraves, I. Luzinov, J. Hensley, L-C. Kimerling and A. Agarwal, Lab Chip, 13, 11, 2161 (2013).

8. M. Nedeljkovic, A. Z. Khokhar, Y. Hu, X. Chen, J. Soler Penades, S.

Stankovic, Opt. Mater. Exp., 3, 9, 1205 (2013).

9. J. Soler Penadés, C. Alonso-Ramos, A. Z. Khokhar, M. Nedeljkovic, A.

Ortega-Moñux, I. Molina-Fernández, P. Cheben, G. Z. Mashanovich, Opt. Lett.

39, 19, 5661 (2014).

10. D. Marris-Morini, V. Vakarin, J. M. Ramirez, Q. Liu, A. Ballabio, J. Frigerio,

M. Montesinos, C. Alonso-Ramos, X. Le Roux, S. Serna, D. Benedikovic, D.

Chrastina, L. Vivien and G. Isella, Nanophotonics, 7, 11, 1781 (2018).
11. M. Muneeb, X. Chen, P. Verheyen, G. Lepage, S. Pathak, E. Ryckeboer, A. Malik, B. Kuyken, M. Nedeljkovic, J. Van Campenhout, and G. Mashanovich, Opt. Express, 21, 10, 11659 (2013).

12. Z. Lin, A. M. Agarwal, L. C. Kimerling and J. Michel, Nanophotonics 3, 4-5, 247 (2014).

13. T.-H. Xiao, Z. Ziqiang, Z. Wen, T. Mitsuru, K. T. Hon, C. Zhenzhou and G. Keisuke, Opt. Lett. 42, 15, 2882 (2017).

14. S. Marchionna, A. Virtuani, M. Acciarri, G. Isella, and H. von Kaenel. Defect imaging of SiGe strain relaxed buffers grown by LEPECVD. Mat. Sci. Semicond. Process. 9 (4--5) 802--805 (2006).

15. J. M. Ramirez, V. Vakarin, J. Frigerio, P. Chaisakul, D. Chrastina, X. Le Roux, A. Ballabio, L. Vivien, G. Isella, and D. Marris-Morini, Opt. Express, 25, 3020 (2017).

16. J. M. Ramirez, V. Vakarin, C. Gilles, J. Frigerio, A. Ballabio, P. Chaisakul, X. Le Roux, C. Alonso-Ramos, G. Maisons, L. Vivien, M. carras, G. Isella, and D. Marris-Morini, Opt. Lett., 42, 1, 105 (2017).

17. V. Vakarin, J. M. Ramirez, J. Frigerio, Q. Liu, A. Ballabio, X. Le Roux, C. Alonso-Ramos, G. Isella, P. Cheben, W. N. Ye, L. Vivien and D. Marris-Morini, Appl. Sci. 8, 1154 (2018).

18. V. Vakarin, J. M. Ramirez, J. Frigerio, A. Ballabio, X. Le Roux, Q. Liu, D. Bouville, L. Vivien, G. Isella and D. Marris-Morini, Opt. Lett. 42, 173482 (2017).

19. Q. Liu, J. M. Ramirez, V. Vakarin, X. Le Roux, C. Alonso-Ramos, J. Frigerio, A. Ballabio, E. Talamas Simola, D. Bouville, L. Vivien, G. Isella and D. MarrisMorini, Opt. Lett. 43, 5021 (2018).

20. Q. Liu, J. M. Ramirez, V. Vakarin, X. Le Roux, J. Frigerio, A. Ballabio, E. Talamas Simola, C. Alonso-Ramos, D. Benedikovic, D. Bouville, L. Vivien, G. Isella and D. Marris-Morini, Accepted in Opt. Express.

21. Q. Liu, J. M. Ramirez, V. Vakarin, X. Le Roux, A. Ballabio, J. Frigerio, D. Chrastina, G. Isella, D. Bouville, L. Vivien, C. Alonso-Ramos and D. MarrisMorini, Opt. Mat. Express, 8, 5, 1305 (2018).

22. W. Bogaerts, P. D. Heyn, T. V. Vaerenbergh, K. D. Vos, S. K. Selvaraja, T. Claes, P. Dumon, P. Bienstman, D. V. Thoughout and R. Baets, Laser Photonics Rev. 6, 1, 47 (2012).

23. Z. Cheng, X. Chen, C. Y. Wong, K. Xu, and H. K. Tsang, IEEE photonics journal, 4, 1510-1519 (2012).

24. R. Shankar, I. Bulu, and M. Lončar, Appl. Phys. Lett. 102, 051108 (2013).

25. A. G. Griffith, R. K. Lau, J. Cardenas, Y. Okawachi, A. Mohanty, R. Fain, Y. H. D. Lee, M. Yu, C. T. Phare, C. B. Poitras, A. L. Gaeta, and M. Lipson, Nat. Comm. 6, 6299 (2015).

26. A. Spott, Y. Liu, T. Baehr-Jones, R. llic, and M. Hochberg, Appl. Phys. Lett. 97, 213501 (2010).

27. A. E. J. Lim, J. Song, Q. Fang, C. Li, X. Tu, N. Duan, K. K. Chen, R. Poh-Cher and T. Y. Liow, IEEE J. Sel. Top. Quantum Electron. 20, 4, 405 (2014).

28. C. Rosenblad, H. R. Deller, A. Dommann, T. Meyer, P. Schroeter, and H. J. Von Kaenel, J. Vac. Sci. Technol. A 16, 2785 (1998).

29. J. M. Ramirez, Q. Liu, V. Vakarin, J. Frigerio, A. Ballabio, X. Le Roux, D. Bouville, L. Vivien, G. Isella and D. Marris-Morini, Opt. Express, 26, 2, 870 (2018).

30. F. Turri, F. Ramiro-Manzano, I. Carusotto, M. Ghulinyan, G. Pucker, and L. Pavesi, J. Lightwav. Technol. 34, 23, 5385-5390 (2016). 


\section{References}

1. R. Soref, "Mid-infrared photonics in silicon and germanium," Nature Photonics, 4, 495 (2010).

2. J. Haas, B. Mizaikoff, "Advances in mid-infrared spectroscopy for chemical analysis," Annual Review of Analytical Chemistry, 9,45 (2016).

3. X. Wang, S. S. Kim, R. Roßbach, M. Jetter, P. Michler, and B. Mizaikoff, "Ultra-sensitive mid-infrared evanescent field sensors combining thin-film strip waveguides with quantum cascade lasers," Analyst, 137, 2322 (2012).

4. Y. Chen, H. Lin, J. Hu and M. Li, "Heterogeneously integrated silicon photonics for the mid-infrared and spectroscopic sensing," ACS nano, 8, 7, 6955 (2014).

5. R. Soref, "The past, the present and the future of silicon photonics, "IEEE J. Sel. Top. Quantum Electron. 12, 6 (2006).

6. S-A. Miller, M. Yu, X. Ji, G. Griffith, J. Cardenas, A-L. Gaeta, and M. Lipson, "Low-loss silicon platform for broadband mid-infrared photonics," Optica, 4, 7, 707 (2017).

7. P-T. Lin, V. Singh, J. Hu, K. Richardson, J-D. Musgraves, I. Luzinov, J. Hensley, L-C. Kimerling and A. Agarwal, "Chip-scale Mid-Infrared chemical sensors using airclad pedestal silicon waveguides," Lab Chip, 13, 11, 2161 (2013).

8. M. Nedeljkovic, A. Z. Khokhar, Y. Hu, X. Chen, J. Soler Penades, S. Stankovic, "Silicon photonic devices and platforms for the mid-infrared," Opt. Mater. Exp., 3, 9 , 1205 (2013).

9. J. Soler Penadés, C. Alonso-Ramos, A. Z. Khokhar, M. Nedeljkovic, A. Ortega-Moñux, I. Molina-Fernández, P. Cheben, G. Z. Mashanovich, "Suspended SOI waveguide with sub-wavelength grating cladding for mid-infrared," Opt. Lett. 39, 19, 5661 (2014).

10. D. Marris-Morini, V. Vakarin, J. M. Ramirez, Q. Liu, A. Ballabio, J. Frigerio, M. Montesinos, C. Alonso-Ramos, X. Le Roux, S. Serna, D. Benedikovic, D. Chrastina, L. Vivien and G. Isella, "Germanium-based integrated photonics from near-to mid-infrared applications," Nanophotonics, 7, 11, 1781 (2018).

11. M. Muneeb, X. Chen, P. Verheyen, G. Lepage, S. Pathak, E. Ryckeboer, A. Malik, B. Kuyken, M. Nedeljkovic, J. Van Campenhout, and G. Mashanovich,

"Demonstration of Silicon-on-insulator mid-infrared spectrometers operating at $3.8 \mu \mathrm{m}$," Opt. Express, 21, 10, 11659 (2013).

12. Z. Lin, A. M. Agarwal, L. C. Kimerling and J. Michel, "Nonlinear Group IV photonics based on silicon and germanium: from near-infrared to mid-infrared," Nanophotonics 3, 4-5, 247 (2014).

13. T.-H. Xiao, Z. Ziqiang, Z. Wen, T. Mitsuru, K. T. Hon, C. Zhenzhou and G. Keisuke, “Mid-infrared germanium photonic crystal cavity," Opt. Lett. 42, 15, 2882 (2017).

14. K. K. Linder, F. C. Zhang, J-S. Rieh, P. Bhattacharya and D. Houghton, "Reduction of dislocation density in mismatched SiGe/Si using a low-temperature Si buffer layer," Appl. Phys. Lett. 70, 24, 3224 (1997).

15. J. M. Ramirez, V. Vakarin, J. Frigerio, P. Chaisakul, D. Chrastina, X. Le Roux, A. Ballabio, L. Vivien, G. Isella, and D. Marris-Morini, " Ge-rich graded-index Si1-xGex waveguides with broadband tight mode confinement and flat anomalous dispersion for nonlinear mid-infrared photonics," Opt. Express, 25, 3020 (2017).

16. J. M. Ramirez, V. Vakarin, C. Gilles, J. Frigerio, A. Ballabio, P. Chaisakul, X. Le Roux, C. Alonso-Ramos, G. Maisons, L. Vivien, M. carras, G. Isella, and D. Marris-

Morini, " Low-loss Ge-rich Si0.2Ge0.8 waveguides for mid-infrared photonics," Opt. Lett., 42, 1, 105 (2017).

17. V. Vakarin, J. M. Ramirez, J. Frigerio, Q. Liu, A. Ballabio, X. Le Roux, C. Alonso-Ramos, G. Isella, P. Cheben, W. N. Ye, L. Vivien and D. Marris-Morini, " Wideband Ge-rich SiGe polarization-insensitive waveguides for mid-infrared free-space communications," Appl. Sci. 8, 1154 (2018).

18. V. Vakarin, J. M. Ramirez, J. Frigerio, A. Ballabio, X. Le Roux, Q. Liu, D. Bouville, L. Vivien, G. Isella and D. Marris-Morini, " Ultra-wideband Ge-rich silicon germanium integrated Mach-Zehnder interferometer for mid-infrared spectroscopy," Opt. Lett. 42, 173482 (2017).

19. Q. Liu, J. M. Ramirez, V. Vakarin, X. Le Roux, C. Alonso-Ramos, J. Frigerio, A. Ballabio, E. Talamas Simola, D. Bouville, L. Vivien, G. Isella and D. Marris-Morini, " Integrated broadband dual-polarization Ge-rich SiGe mid-infrared Fourier-transform spectrometer," Opt. Lett. 43, 5021 (2018).

20. Q. Liu, J. M. Ramirez, V. Vakarin, X. Le Roux, J. Frigerio, A. Ballabio, E. Talamas Simola, C. Alonso-Ramos, D. Benedikovic, D. Bouville, L. Vivien, G. Isella and D. Marris-Morini, "On-chip Bragg grating waveguides and Fabry-Perot resonators for long-wave infrared operation up to $8.4 \mu \mathrm{m}$," Submitted to Opt. Express

21. Q. Liu, J. M. Ramirez, V. Vakarin, X. Le Roux, A. Ballabio, J. Frigerio, D. Chrastina, G. Isella, D. Bouville, L. Vivien, C. Alonso-Ramos and D. Marris-Morini, " Midinfrared sensing between 5.2 and $6.6 \mu \mathrm{m}$ wavelengths using Ge-rich SiGe waveguides," Opt. Mat. Express, 8, 5, 1305 (2018).

22. W. Bogaerts, P. D. Heyn, T. V. Vaerenbergh, K. D. Vos, S. K. Selvaraja, T. Claes, P. Dumon, P. Bienstman, D. V. Thoughout and R. Baets, "Silicon microring resonators," Laser Photonics Rev. 6, 1, 47 (2012).

23. Z. Cheng, X. Chen, C. Y. Wong, K. Xu, and H. K. Tsang, "Mid-infrared suspended membrane waveguide and ring resonator on silicon-on-insulator," IEEE photonics journal, 4, 1510-1519 (2012).

24. R. Shankar, I. Bulu, and M. Lončar, “Integrated high-quality factor silicon-on-sapphire ring resonators for the mid-infrared," Appl. Phys. Lett. 102, 051108 (2013).

25. A. G. Griffith, R. K. Lau, J. Cardenas, Y. Okawachi, A. Mohanty, R. Fain, Y. H. D. Lee, M. Yu, C. T. Phare, C. B. Poitras, A. L. Gaeta, and M. Lipson, "Silicon-chip midinfrared frequency comb generation," Nat. Comm. 6, 6299 (2015).

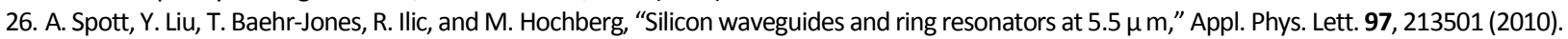

27. A. E. J. Lim, J. Song, Q. Fang, C. Li, X. Tu, N. Duan, K. K. Chen, R. Poh-Cher and T. Y. Liow, "Review of silicon photonics foundry efforts," IEEE J. Sel. Top. Quantum Electron. 20, 4, 405 (2014).

28. C. Rosenblad, H. R. Deller, A. Dommann, T. Meyer, P. Schroeter, and H. J. Von Kaenel, "Silicon epitaxy by low-energy plasma enhanced chemical vapor deposition," J. Vac. Sci. Technol. A 16, 2785 (1998).

29. J. M. Ramirez, Q. Liu, V. Vakarin, J. Frigerio, A. Ballabio, X. Le Roux, D. Bouville, L. Vivien, G. Isella and D. Marris-Morini, "Graded SiGe waveguides with broadband low-loss propagation in the mid infrared," Opt. Express, 26, 2, 870 (2018).

30. F. Turri, F. Ramiro-Manzano, I. Carusotto, M. Ghulinyan, G. Pucker, and L. Pavesi, "Wavelength dependence of a vertically coupled resonator-waveguide system,’ J. Lightwav. Technol. 34, 23, 5385-5390 (2016). 
